\title{
PENGENALAN CITRA WAJAH DENGAN MENGGUNAKAN TRANSFORMASI WAVELET DISKRIT DAN JARINGAN SARAF TIRUAN BACK-PROPAGATION
}

\author{
Suhendry Effendy \\ Jurusan Teknik Informatika, Fakultas Ilmu Komputer, Bina Nusantara University \\ Jln. K.H. Syahdan No. 9, Palmerah, Jakarta Barat 11480 \\ seffendy@binus.edu
}

\begin{abstract}
This paper discusses the facial image recognition system using Discrete Wavelet Transform and backpropagation artificial neural network. Discrete Wavelet Transform processes the input image to obtain the essential features found on the face image. These features are then classified using an back-propagation artificial neural network for the input image to be identified. Testing the system using facial images in AT \& T Database of Faces of 400 images comprising 40 facial images of individuals and web-camera catches as many as 100 images of 10 individuals. The accuracy of level of recognition on AT \& T Database of Faces reaches 93.5\%, while the accuracy of level of recognition on a web-camera capture images up to 96\%. Testing is also done on image of AT \& T Database of Faces with given noise. Apparently the noise in the image does not give meaningful effect on the level of recognition accuracy.
\end{abstract}

Keywords: face recognition, discrete wavelet transformation, artificial neural network, back-propagation

\begin{abstract}
ABSTRAK
Makalah ini membahas mengenai sistem pengenalan citra wajah dengan menggunakan Transformasi Wavelet Diskrit dan jaringan saraf tiruan back-propagation. Transformasi Wavelet Diskrit memproses citra masukan untuk mendapatkan fitur penting yang terdapat pada citra wajah. Fitur tersebut kemudian diklasifikasikan dengan menggunakan jaringan saraf tiruan back-propagation agar citra masukan dapat diidentifikasi. Pengujian sistem menggunakan citra wajah dari AT\&T Database of Faces sebanyak 400 citra yang terdiri dari 40 individu dan citra wajah hasil tangkapan web-camera sebanyak 100 citra yang terdiri dari 10 individu. Tingkat akurasi pengenalan pada AT\&T Database of Faces mencapai 93.5\%, sedangkan tingkat akurasi pengenalan pada citra tangkapan web-camera mencapai 96\%. Pengujian juga dilakukan terhadap citra AT\&T Database of Faces yang diberi noise. Ternyata noise pada citra tidak memberikan pengaruh yang berarti terhadap tingkat akurasi pengenalan.
\end{abstract}

Kata kunci: Pengenalan wajah, Transformasi Wavelet Diskrit, jaringan saraf tiruan, back-propagation 


\section{PENDAHULUAN}

Pengenalan citra wajah dewasa ini telah menjadi bidang khusus dalam computer vision. Salah satu pemicu berkembangnya berbagai teknik pengenalan citra wajah adalah meningkatnya kebutuhan akan sistem identifikasi biometric yang dapat bekerja efisien serta memiliki tingkat akurasi tinggi. Pengenalan citra wajah memerlukan teknik pengolahan dan pengenalan citra tingkat tinggi karena wajah manusia memiliki tingkat kompleksitas yang sangat tinggi. Disamping itu, variasi wajah yang mungkin terdapat di dalam satu wajah individu bisa sangat besar sehingga semakin menyulitkan kita untuk membangun suatu sistem pengenalan wajah.

Berbagai penelitian telah dilakukan untuk menemukan teknik pengenalan wajah yang dapat bekerja efisien serta menghasilkan tingkat akurasi pengenalan yang tinggi. Salah satu metode pengenalan yang sudah cukup dikenal adalah dengan menggunakan Principal Component Analysis (PCA) yang mampu menghasilkan tingkat akurasi yang cukup baik. Namun metode PCA membutuhkan waktu yang relatif lama untuk melakukan rekompilasi terhadap citra dalam database guna menghasilkan eigenface yang dibutuhkan pada metode ini. Selain itu, metode ini juga memerlukan kapasitas database yang lebih besar untuk menyimpan eigenfaces yang dihasilkan. Dari permasalahan di atas, timbul gagasan untuk melakukan proses pengenalan wajah tanpa melibatkan proses rekompilasi seperti pada metode PCA. Salah satu metode yang dapat digunakan adalah dengan menerapkan Transformasi Wavelet Diskrit untuk mengolah sinyal atau informasi yang terdapat pada citra wajah. Pada makalah ini, dibahas mengenai suatu metode yang mengkombinasikan Transformasi Wavelet Diskrit dengan metode klasifikasi jaringan saraf tiruan back-propagation untuk menghasilkan suatu sistem pengenalan wajah yang memiliki tingkat akurasi yang tinggi.

\section{METODE}

Pada sistem pengenalan wajah dengan bantuan komputer, fungsi indra penglihatan dapat ditangani oleh berbagai media seperti kamera digital, scanner, atau web-camera. Citra wajah yang diinput melalui media tersebut kemudian diproses melalui berbagai perhitungan dengan bantuan komputer sehingga sistem mampu mengenali citra wajah tersebut. Sistem pengenalan wajah terbagi menjadi dua bagian utama, yaitu : pelatihan pola masukan dan identifikasi wajah (Gambar 1). Pada pelatihan pola masukan, citra input diolah dan dilatih agar sistem dapat mengenali pola dari citra wajah tersebut. Sedangkan pada identifikasi wajah, citra input diolah dan kemudian diklasifikasikan ke dalam kelas atau subjek tertentu sesuai dengan data dan informasi hasil proses pelatihan sebelumnya.

\section{Pengolahan Awal Citra}

Pemrosesan awal yang dilakukan terhadap citra input adalah grayscaling dan normalisasi histogram. Proses grayscaling diperlukan karena informasi yang dibutuhkan oleh sistem pengenalan wajah adalah nilai intensitas atau tingkat keabuan dari citra, sehingga komponen warna pada citra diabaikan. Sedangkan normalisasi histogram dilakukan untuk memperbaiki sebaran cahaya pada citra.

\section{Transformasi Wavelet}

Transformasi Wavelet Diskrit dilakukan dengan menerapkan konvolusi low-pass filter $(H)$ untuk mendapatkan sinyal global dan high-pass filter $(G)$ untuk mendapatkan sinyal detil. Karena citra wajah input berada pada bidang dimensi dua, maka konvolusi diterapkan dua kali yaitu pada kolom dan baris citra input, sehingga satu kali proses Transformasi Wavelet Diskrit akan menghasilkan satu citra global dan tiga citra detil. 


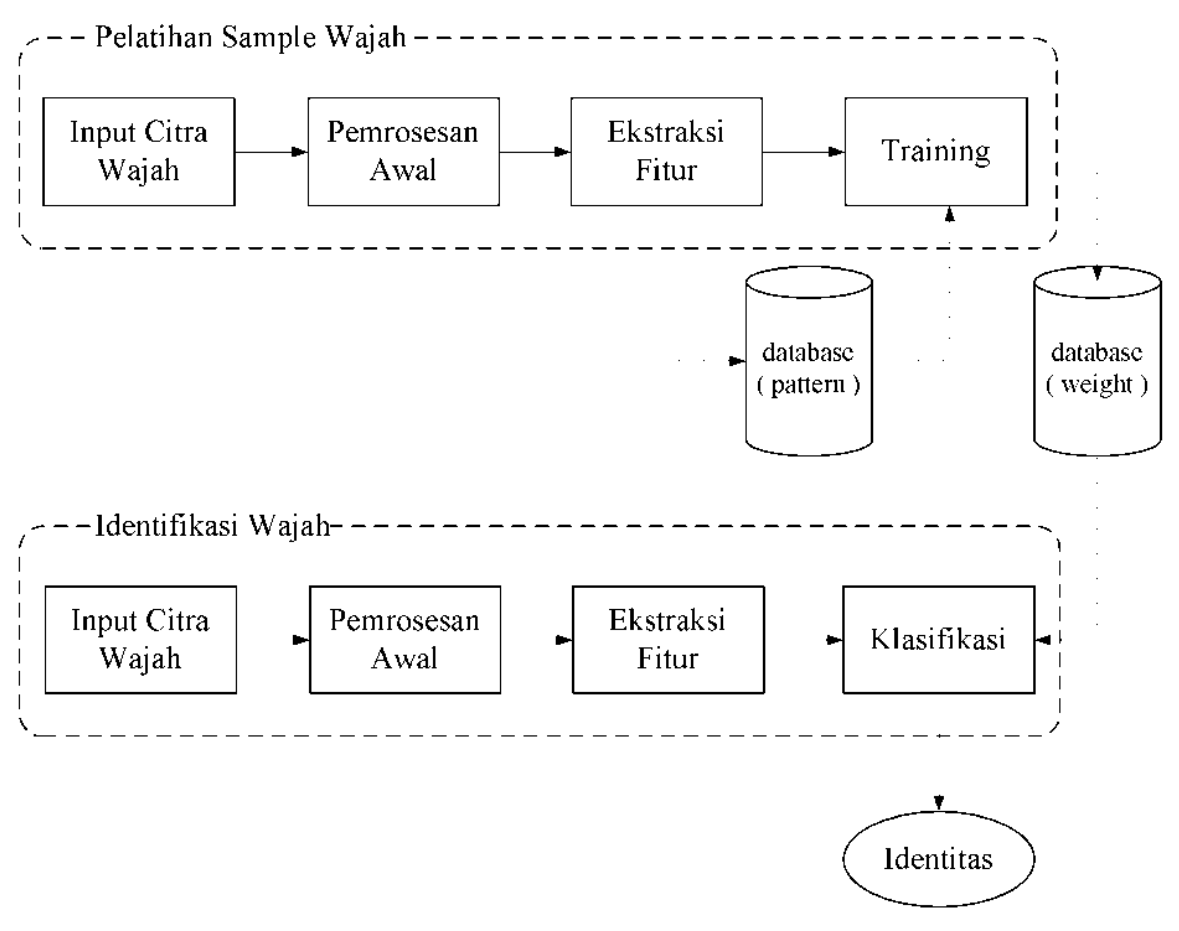

Gambar 1. Tahap dalam Sistem Pengenalan Wajah

Citra global hasil dekomposisi wavelet didekomposisikan kembali untuk mendapatkan citra global dan citra detil pada level berikutnya. Dengan demikian, dekomposisi wavelet pada level-n adalah sebagai berikut. Contoh dekomposisi wavelet 3 level terdapat pada Gambar 2.

$$
\begin{array}{lll}
A_{n}=\left[H_{x} *\left[H_{y} * A_{n-1}\right]_{2,1}\right]_{1,2} & \ldots \ldots .(1) & D_{n 2}=\left[G_{x} *\left[H_{y} * A_{n-1}\right]_{2,1}\right]_{1,2} \\
D_{n 1}=\left[H_{x} *\left[G_{y} * A_{n-1}\right]_{2,1}\right]_{1,2} & \ldots \ldots .(2) & D_{n 3}=\left[G_{x} *\left[G_{y} * A_{n-1}\right]_{2,1}\right]_{1,2}
\end{array}
$$

Tanda * merupakan operasi konvolusi. Tanda [.. $]_{2,1}$ merupakan sub-sampling sepanjang baris, dan $[. .]_{1,2}$ adalah sub-sampling sepanjang kolom. $A_{n}$ adalah citra pendekatan hasil dekomposisi wavelet pada level-n yang didapatkan melalui proses low-pass filter pada baris dan kolom citra input $\left(A_{0}\right.$ adalah citra asli). $D_{n}$ adalah citra detil pada level-n yang didapatkan melalui proses low-pass filter dan high-pass filter pada baris dan kolom dimana $D_{n 1}$ merupakan citra detil horisontal, $D_{n 2}$ adalah citra detil vertikal, dan $D_{n 3}$ adalah citra detil diagonal. $H$ dan $G$ adalah low-pass filter dan high-pass filter.

Citra global (koefisien DWT global) kemudian digunakan sebagai input pada jaringan saraf tiruan back-propagation setelah nilainya dinormalisasi. Normalisasi koefisien DWT global dilakukan dengan membagi nilainya dengan nilai maksimum yang dapat dihasilkan dari proses dekomposisi wavelet pada level tersebut.

\section{Back-Propagation}

Disain jaringan saraf tiruan back-propagation yang digunakan adalah sebagai berikut.

- $\quad$ Jumlah hidden layer yang digunakan adalah satu. 
- $\quad$ Fungsi aktivasi yang digunakan adalah fungsi sigmoid karena nilai keluaran yang diinginkan berada pada jangkauan 0 hingga 1 .

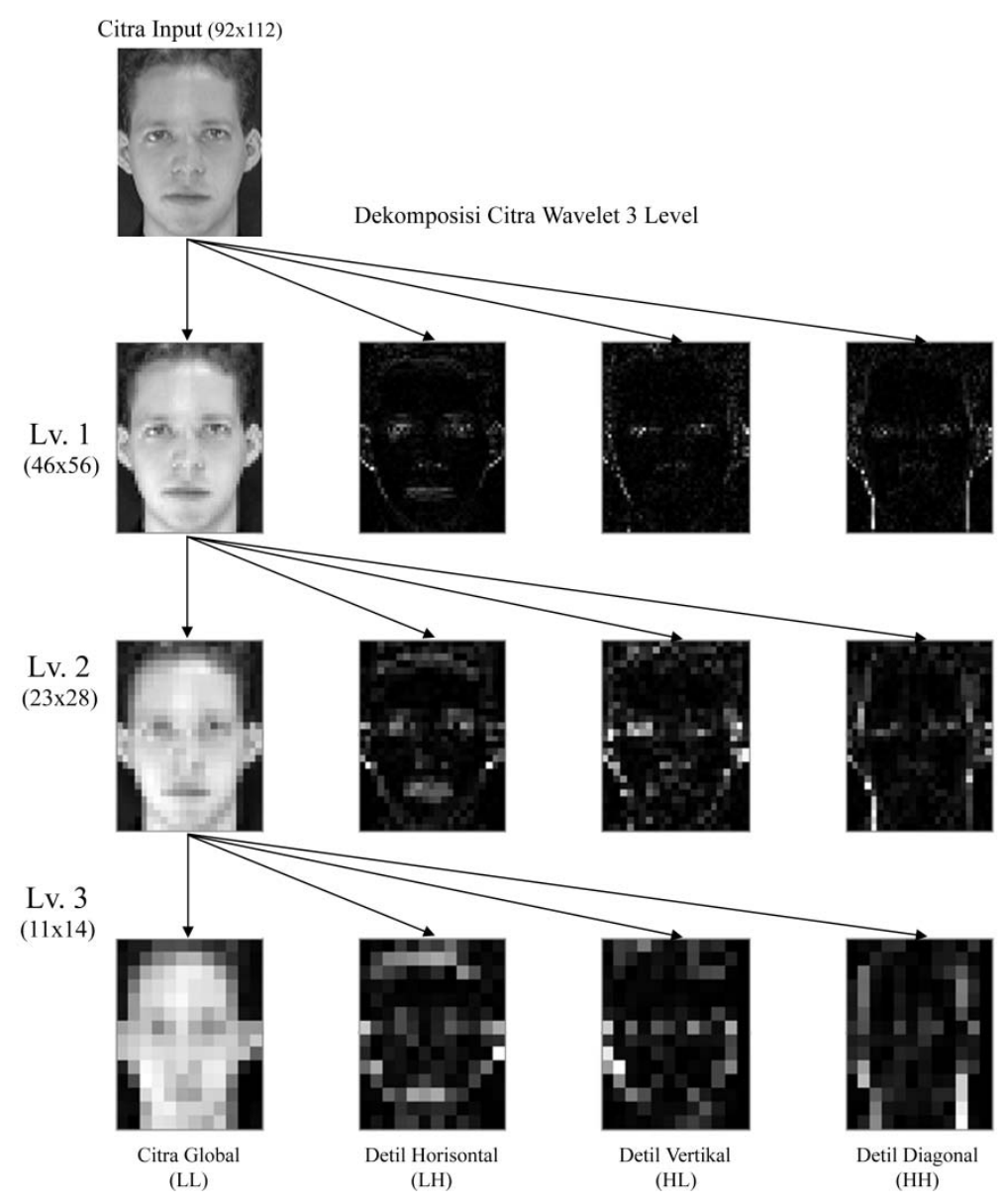

Gambar 2. Dekomposisi Wavelet 3 Level

\section{Strategi Representasi Data Output}

Masing-masing node pada output layer mewakili sebuah kode identitas subjek. Untuk tahap pelatihan, nilai 0,95 digunakan sebagai input pada node di output layer yang mewakili kode identitas subjek tersebut, sedangkan node lainnya diberikan nilai 0,05 . Untuk tahap identifikasi, kode identitas subjek ditentukan oleh node yang memiliki nilai tertinggi pada output layer (winner take all). Jumlah node yang dibutuhkan pada output layer adalah sebanyak jumlah subjek.

\section{HASIL DAN PEMBAHASAN}

\section{Prosedur Pengujian}

Pengujian pada aplikasi pengenal wajah ini dilakukan pada dua kelompok data, yaitu: pengujian menggunakan data AT\&T Database of Faces dan pengujian menggunakan data citra tangkapan web-camera. Masing-masing kelompok data terdiri dari subjek yang masing-masing memiliki 10 citra wajah. Dari 10 citra wajah tersebut kemudian dikelompokan menjadi dua kelompok 
yang masing-masing terdiri dari 5 citra wajah. Kelompok pertama digunakan sebagai sampel untuk pelatihan, sedangkan kelompok kedua digunakan sebagai sampel untuk pengujian. Pemisahan ini dimaksudkan agar sampel yang digunakan untuk pelatihan tidak digunakan kembali pada saat pengujian. Pengujian yang dilakukan meliputi pengujian terhadap konfigurasi jaringan saraf tiruan back-propagation, pengujian pengaruh level dekomposisi wavelet, dan pengujian terhadap pengaruh jumlah subjek dan jumlah pola tiap subjek yang dilatih.

\section{Evaluasi pada AT\&T Database of Faces}

AT\&T Database of Faces (Gambar 3) memiliki 40 subjek dengan masing-masing 10 citra wajah, sehingga jumlah seluruh citra wajah yang ada adalah 400 buah. Citra yang terdapat pada AT\&T Database of Faces adalah citra grayscale dengan ukuran 92 x 112 piksel.

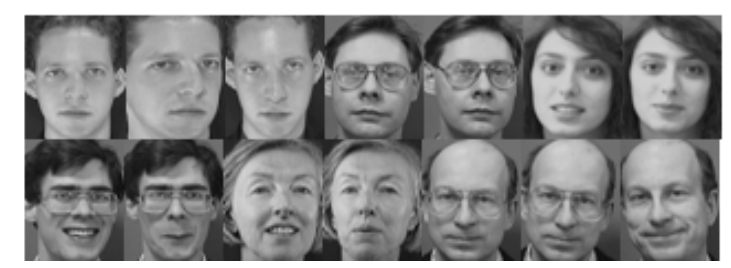

Gambar 3. Beberapa Citra Wajah pada AT\&T Database of Faces

\section{Evaluasi Berdasarkan Jumlah Subjek pada AT\&T Databases of Faces}

Pada pengujian ini, sistem diuji berdasarkan perubahan / variasi jumlah subjek pada AT\&T Database of Faces. Jumlah hidden node pada konfigurasi jaringan saraf tiruan back-propagation yang digunakan adalah 155 yang didapatkan dari hasil pengujian sebelumnya. Jumlah subjek yang diuji adalah 2 sampai 40. Hasil pengujian dapat dilihat pada tabel 1.

Tabel 1. Ringkasan Hasil Pengujian Jumlah Subjek pada AT\&T Database of Faces

\begin{tabular}{ccr}
\hline Jumlah Subjek & $\begin{array}{c}\text { Jumlah Citra yang Salah Diklasifikasikan / } \\
\text { Jumlah Citra yang Diuji }\end{array}$ & Akurasi Pengenalan \\
\hline 10 & $0 / 50$ & $100 \%$ \\
20 & $6 / 100$ & $94 \%$ \\
30 & $7 / 150$ & $95.33 \%$ \\
40 & $13 / 200$ & $93.50 \%$ \\
\hline
\end{tabular}

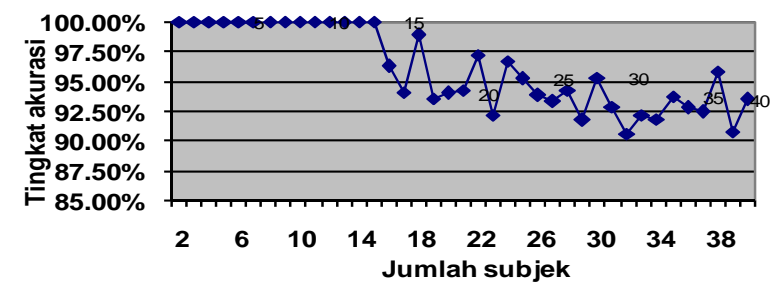

Gambar 4. Grafik Pengaruh Jumlah Subjek terhadap Perubahan Tingkat Akurasi Pengenalan pada AT\&T Database Of Faces 
Dari hasil pengujian ini, dapat dilihat bahwa penambahan jumlah subjek cenderung mengakibatkan penurunan tingkat akurasi pengenalan. Grafik pada gambar 4 menunjukan tingkat akurasi pengenalan bervariasi dari 100\% hingga 90.63\%.

\section{Evaluasi Berdasarkan Level Domposisi Wavelet pada AT\&T Databases of Faces}

Pengujian ini bertujuan untuk mengevaluasi pengaruh perubahan level dekomposisi wavelet yang digunakan pada saat ekstraksi fitur. Level dekomposisi yang diuji dimulai dari 2 sampai 5 dengan konfigurasi jaringan saraf tiruan back-propagation sama seperti pengujian sebelumnya.

Tabel 2. Ringkasan Hasil Pengujian Level Dekomposisi Wavelet pada AT\&T Database of Faces

\begin{tabular}{ccc}
\hline $\begin{array}{c}\text { Level Dekomposisi } \\
\text { Wavelet }\end{array}$ & $\begin{array}{c}\text { Jumlah Citra yang Salah } \\
\text { Diklasifikasikan / Jumlah Citra } \\
\text { yan Diuji }\end{array}$ & $\begin{array}{c}\text { Akurasi } \\
\text { Pengenalan }\end{array}$ \\
\hline 2 & 14 / 200 & $93 \%$ \\
3 & 13 / 200 & $93.50 \%$ \\
4 & $21 / 200$ & $89.50 \%$ \\
5 & 98 / 200 & $51 \%$ \\
\hline
\end{tabular}

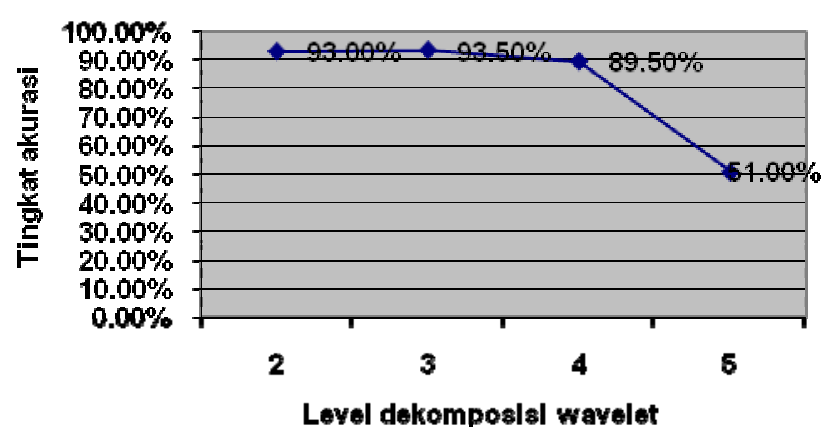

Gambar 5. Grafik Pengaruh Level Dekomposisi Wavelet terhadap Tingkat Akurasi Pengenalan pada AT\&T Database Of Faces

Dari hasil pengujian ini, dapat dilihat bahwa penggunaan level dekomposisi wavelet yang berbeda akan mempengaruhi tingkat akurasi pengenalan. Hal menarik dari data di atas adalah tingkat akurasi yang dihasilkan pada dekomposisi level-3 lebih tinggi dibandingkan dekomposisi level-2, namun pada dekomposisi level-4 dan level-5, tingkat akurasi pengenalannya mengalami penurunan drastis.

\section{Evaluasi pada Citra Tangkapan Web-Camera}

Data pada citra tangkapan web-camera terdiri dari 10 subjek dengan masing-masing 10 citra wajah (berwarna) dengan ukuran 90x120 piksel. 


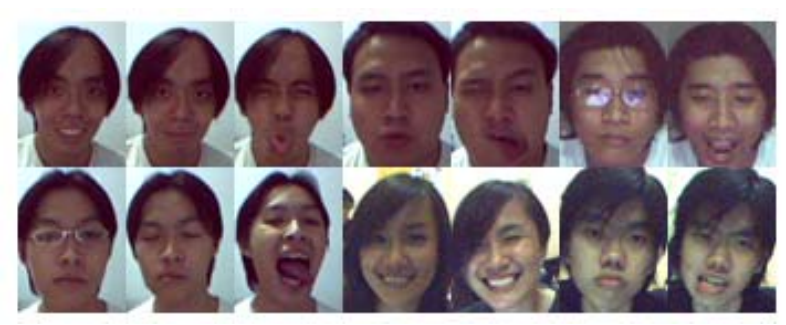

Gambar 6. Beberapa Citra Wajah pada Citra Tangkapan Web-Camera.

Perbedaan utama citra tangkapan web-camera dengan citra AT\&T Database of Faces adalah :

1. Citra tangkapan web-camera memiliki kualitas yang lebih rendah dari pada citra AT\&T Database of Faces. Hal ini disebabkan oleh banyaknya noise akibat ketajaman dan refresh rate yang rendah dari web-camera yang digunakan.

2. Variasi kondisi tiap wajah subjek pada citra tangkapan web-camera lebih banyak (posisi wajah, posisi rambut, ekspresi wajah, atribut yang dikenakan).

\section{Evaluasi Berdasarkan Jumlah Subjek pada Citra Tangkapan Web-Camera}

Pengujian ini serupa dengan pengujian pada AT\&T Database of Faces, namun citra yang digunakan berasal dari citra tangkapan web-camera. Jumlah hidden node yang digunakan adalah 150 dengan jumlah subjek yang diuji dari 2 hingga 10.

Tabel 3. Ringkasan Hasil Pengujian Jumlah Subjek pada Citra Tangkapan Web-Camera

\begin{tabular}{ccr}
\hline Jumlah Subjek & $\begin{array}{c}\text { Jumlah Citra yang Salah } \\
\text { Diklasifikasikan / Jumlah Citra } \\
\text { yang Diuji }\end{array}$ & \multicolumn{1}{c}{$\begin{array}{c}\text { Akurasi } \\
\text { Pengenalan }\end{array}$} \\
\hline 4 & $1 / 20$ & $95 \%$ \\
6 & $0 / 30$ & $100 \%$ \\
8 & $1 / 40$ & $97.50 \%$ \\
10 & $2 / 50$ & $96 \%$ \\
\hline
\end{tabular}

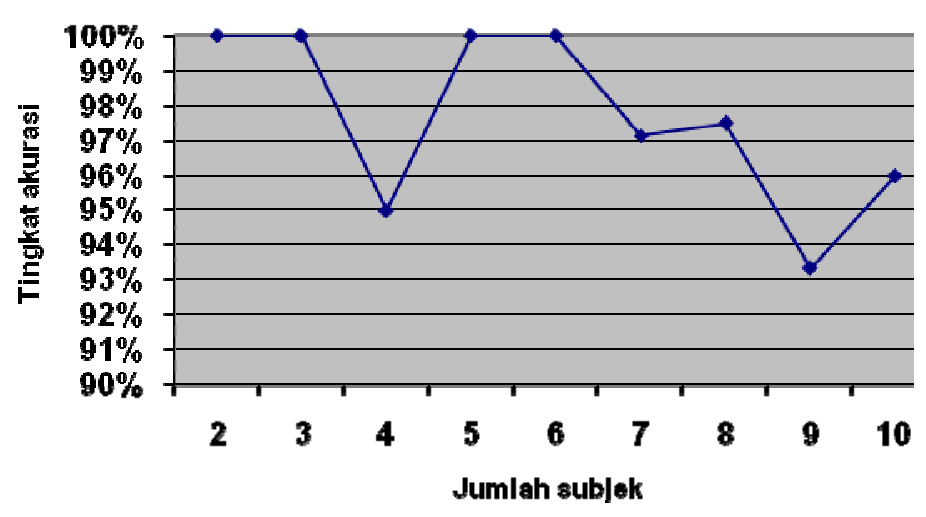

Gambar 7. Grafik Pengaruh Jumlah Subjek terhadap Perubahan Tingkat Akurasi pada Citra Tangkapan Web-Camera. 
Dari hasil pengujian ini, dapat dilihat bahwa akurasi pengenalan pada citra tangkapan webcamera rata-rata lebih rendah bila dibandingkan hasil pengujian pada AT\&T Database of Faces untuk jumlah subjek yang sama.

\section{Evaluasi Berdasarkan Level Domposisi Wavelet pada Citra Tangkapan Web-Camera}

Pengujian ini serupa dengan pengujian level dekomposisi wavelet pada citra AT\&T Database of Faces namun citra yang digunakan adalah citra tangkapan web-camera. Level dekomposisi yang diuji adalah 1 hingga 5 dengan menggunakan konfigurasi jaringan saraf tiruan back-propagation yang sama dengan pengujian sebelumnya.

Tabel 4. Ringkasan Hasil Pengujian Level Dekomposisi Wavelet pada Citra Tangkapan Web-Camera

\begin{tabular}{ccc}
\hline $\begin{array}{c}\text { Level Dekomposisi } \\
\text { Wavelet }\end{array}$ & $\begin{array}{c}\text { Jumlah Citra yang Salah } \\
\text { Diklasifikasikan / Jumlah } \\
\text { Citra yan Diuji }\end{array}$ & $\begin{array}{c}\text { Akurasi } \\
\text { Pengenalan }\end{array}$ \\
\hline 1 & 5 / 50 & $90 \%$ \\
2 & $3 / 50$ & $94 \%$ \\
3 & 2 / 50 & $96 \%$ \\
4 & $2 / 50$ & $96 \%$ \\
5 & $19 / 50$ & $62 \%$ \\
\hline
\end{tabular}

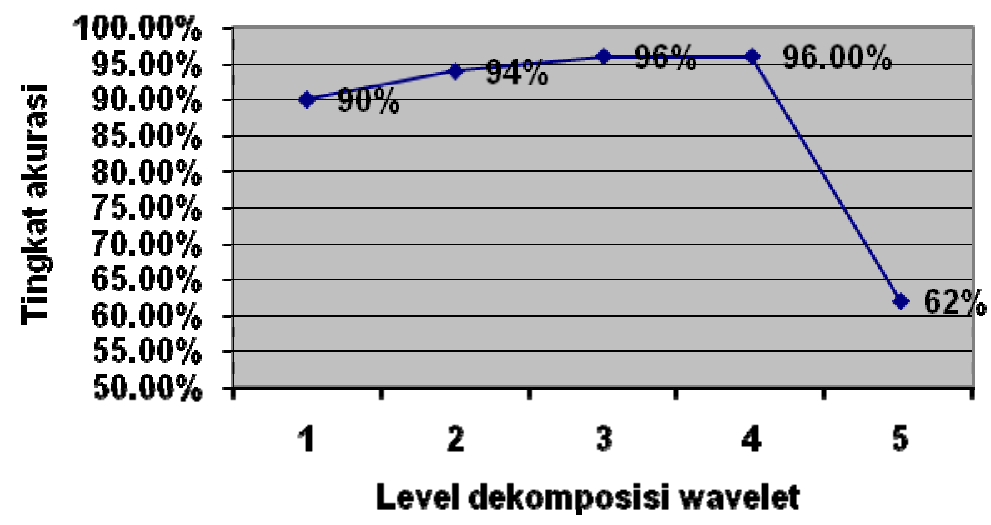

Gambar 8. Grafik Pengaruh Level Dekomposisi Wavelet terhadap Tingkat Akurasi Pengenalan pada Citra Tangkapan Web-Camera

Hasil pengujian ini serupa dengan hasil pengujian AT\&T Database of Faces, yaitu tingkat akurasi pengenalan mengalami peningkatan hingga level dekomposisi tertentu dan kemudian menurun drastis jika didekomposisi lebih lanjut.

\section{Evaluasi Pengaruh Noise}

Pengujian ini bertujuan untuk mengevaluasi pengaruh noise terutama yang terdapat pada citra tangkapan web-camera. Evaluasi dilakukan dengan membandingkan tingkat akurasi pada citra AT\&T Database of Faces tanpa noise, AT\&T Database of Faces diberi noise, dan citra tangkapan web- 
camera. Pengujian dilakukan dengan menggunakan variasi jumlah data / citra pelatihan per subjek. Jumlah subjek yang digunakan untuk pengujian ini adalah 10 .

Tabel 5. Ringkasan Hasil Pengujian Pengaruh Noise

\begin{tabular}{cccc}
\hline \multirow{2}{*}{$\begin{array}{c}\text { Jumlah Data } \\
\text { Pelatihan Per } \\
\text { Subjek }\end{array}$} & $\begin{array}{c}\text { Akurasi Pengenalan } \\
\text { FT\&T Database of } \\
\text { Faces Tanpa } \\
\text { Noise }\end{array}$ & $\begin{array}{c}\text { AT\&T Database of } \\
\text { Faces Diberi } \\
\text { Noise }\end{array}$ & Web-Camera \\
\hline 1 & $86 \%$ & $86 \%$ & $74 \%$ \\
2 & $94 \%$ & $94 \%$ & $78 \%$ \\
3 & $96 \%$ & $96 \%$ & $82 \%$ \\
4 & $96 \%$ & $98 \%$ & $94 \%$ \\
5 & $100 \%$ & $98 \%$ & $96 \%$ \\
\hline
\end{tabular}

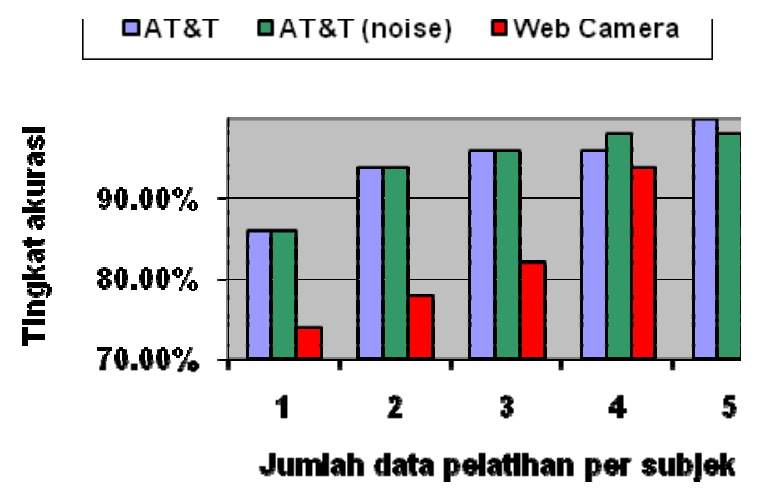

Gambar 9. Grafik Perbandingan Tingkat Akurasi Pengenalan Akibat Pengaruh Noise

Dari hasil pengujian di atas, dapat dilihat bahwa tingkat akurasi pada citra AT\&T tanpa noise dan dengan noise tidak mengalami perubahan yang signifikan. Namun pada pengujian dengan data citra tangkapan web-camera tingkat akurasinya lebih rendah dibandingkan dengan tingkat akurasi pada data $A T \& T$. Dengan demikian dapat diambil simpulan bahwa penyebab utama penurunan tingkat akurasi pada penggunaan web-camera bukan pada noise atau kualitas citra yang dihasilkan, melainkan pada variasi kondisi dari tiap subjek dalam citra.

\section{SIMPULAN}

Kombinasi Transformasi Wavelet Diskrit dan jaringan saraf tiruan back-propagation mampu menghasilkan suatu sistem pengenalan wajah dengan tingkat akurasi yang cukup tinggi. Penambahan level dekomposisi wavelet akan meningkatkan tingkat akurasi pengenalan sampai tingkat tertentu, dan jika sesudahnya proses dekomposisi wavelet masih terus dilakukan maka tingkat akurasi akan menurun karena informasi yang dihasilkan semakin sedikit dan umum. 
Transformasi Wavelet Diskrit mampu memperkecil pengaruh yang disebabkan oleh noise pada citra masukan. Hal ini disebabkan karena fitur yang digunakan untuk pengenalan adalah koefisien DWT citra global yang tidak peka terhadap noise. Penggunaan koefisien DWT citra detil yang dihasilkan melalui Transformasi Wavelet Diskrit pada sistem yang dibuat hanya mengakibatkan penurunan tingkat akurasi.

Jaringan saraf tiruan back-propagation akan bekerja dengan tingkat akurasi yang lebih baik jika jumlah data pelatihan yang digunakan untuk tiap subjek semakin banyak.

\section{DAFTAR PUSTAKA}

Anil, K., Jain (1989). Fundamentals of Digital Image Processing. New Jersey: Prentice-Hall Inc.

Fairhust, M. G. (1988). Computer Vision for Robotic System: An Introduction. Canterbury: PrenticeHall Inc..

Forsyth, D.A., Ponce, J. (2003). Computer Vision: A Modern Approach. Upper Saddle River: Pearson Education.

Gonzales, R.C., Woods, R.E. (1993). Digital Image Processing. Addison Wesley Publishing Company, Inc.

Graps, A. (1995). An Introduction to Wavelets. IEEE Computational Science and Engineering, Vol 2(2): 50-61.

Haykin, S. (1999). Neural Network: A Comprehensive Foundation. New Jersey: Prentice-Hall, Inc.

Kulkarni, A.D. (2001). Computer Vision and Fuzzy-Neural Systems. New Jersey: Prentice-Hall, Inc.

Nixon, M.S., Aguado, A.S. (2002). Feature Extraction \& Image Processing. London: Newnes. Russel, S., Norvig, P. (2003). Aritificial Intelligence: A Modern Approach, Second Edition. New Jersey: Pearson Education, Inc.

Schalkoff, R.J. (1989). Digital Image Processing and Computer Vision. Canada: John Wiley \& Sons, Inc.

Shapiro, L.G., Stockman, G.C. (2001). Computer Vision. New Jersey: Prentice-Hall Inc. 